\title{
Forensic mycology: current perspectives
}

This article was published in the following Dove Press journal:

Research and Reports in Forensic Medical Science

10 December 2015

Number of times this article has been viewed

\section{David L Hawksworth $1-4$ Patricia EJ Wiltshire 4,5 \\ 'Department of Plant Biology II, Faculty of Pharmacy, Complutense University of Madrid, Madrid, Spain; ${ }^{2}$ Comparative Plant and Fungal Biology, Royal Botanic Gardens, Kew, Surrey, ${ }^{3}$ Department of Life Sciences, The Natural History Museum, London, ${ }^{4}$ Geography and Environment, University of Southampton, Southampton, ${ }^{5}$ Department of Geography and Environment, University of Aberdeen, Aberdeen, UK}

Correspondence: David L Hawksworth Departamento de Biología Vegetal II, Facultad de Farmacia, Universidad Complutense de Madrid, Plaza Ramón y Cajal, Madrid 28040, Spain

Tel +44 I3 72272087

Email d.hawksworth@nhm.ac.uk
Abstract: Mycology can contribute to a variety of forensic investigations, including the determination of postmortem intervals from mold growth on corpses, psychoactive substances and toxins, hazards from mold growth in buildings, and providing trace evidence linking people and objects with places. Studies are also starting to be undertaken to explore the use of molecular data on fungi in the characterization of soils. In addition, where there are health concerns, possibly associated with mold growth in buildings, guidance is presented with respect to the collection of samples, and some caveats are given which must be considered in interpretation of data. Attention is drawn to pertinent publications which either appeared, or came to the attention of the authors, since the review they prepared in 2010. This is supplemented by examples from their own recent casework. In order to avoid valuable information being overlooked, there is a need for investigating officers, and those involved in forensic medicine, especially pathologists and toxicologists, to be aware of the evidential value of fungi. In particular, they should not overlook opportunities to recover spores from human remains, to examine any mold colonies growing on corpses, and to analyze gut contents for fungal material and spores.

Keywords: fungi, mold, pollen, postmortem interval, spores, toxicology

\section{Opening comments}

It is gradually becoming more widely appreciated that mycology (the study of fungi) contributes greatly to the provision of intelligence, and to the resolution of evidence in various kinds of criminal and civil forensic investigations.

A review, illustrating the range of applications of mycology in actual criminal investigations, was prepared in 2010, ${ }^{1}$ and the present contribution draws attention to additional examples and experimental studies, especially ones published since that date. Also, we now extend the scope to civil investigations which have a health or medical aspect. This review is written for coroners, pathologists, toxicologists, and investigators concerned with both criminal cases and insurance claims. Through drawing attention to what has been achieved in actual cases, it aims to provide guidance as to where specialist mycological input could be beneficial. Some common pitfalls in sampling and interpretation, particularly in investigations of mold growth in buildings, and ingestion of psychotropic and toxic substances, can lead to unsound claims of adverse medical effects from fungi.

\section{Introduction}

Our first review of forensic mycology ${ }^{1}$ focussed on its application in actual criminal cases; the review endeavored to cover literature and casework to mid-2010. 
This follow-up contribution draws attention to work carried out since that time, and a few studies of which we were unaware previously. We also extend the scope to issues concerned with civil investigations where there are medical implications.

The review of forensic mycology by Said Al Na'imi came to our attention after our first review appeared; it is complementary in that it also covers aspects of mycology that are not involved with criminal investigation.

\section{Postmortem interval}

There is continuing interest in the possibilities of using fungi and prokaryotes (bacteria) associated with human decomposition to indicate postmortem interval (PMI). ${ }^{3}$ A microbial clock has been developed using culture independent highthroughput sequencing in a model system, in which mouse corpses were placed on soil and decomposition monitored for 48 days. During the observation, samples were taken from the grave soil, abdominal cavity, and skin. ${ }^{4}$ The data from bacterial groups and a nematode, rather than any fungi, enabled a prediction to be made with an accuracy of approximately 3 days in this model system. The authors suggest that the method may be developed into a forensic tool although, in the case of human burials, there are so many physicochemical interacting variables (such as soil type, chemistry, redox potential, and water availability), ${ }^{5}$ it is difficult to envisage how any robust estimates of evidential value can be expected from this approach in the foreseeable future.

Direct observations on human cadavers buried in soil in Russia demonstrated that soil fungi were able to grow through the skin and clothes by the second week after burial, that the fungi involved were authochthonous (authochthonous: belonging to that place), and that they corresponded to those recovered directly from the burial places. ${ }^{6,7}$ The reported fungi were all common soil fungi, and were only named to genus. This Russian research group extended their mycological studies and, by combining them with entomological data, developed criteria for the estimation of PMI of bodies buried in soil, salt, and freshwater. ${ }^{8}$

Fungal cultures were grown from samples taken from 60 human corpses in different stages of decomposition (ie, bloated, putrefied, and skeletonized), obtained from a morgue, fields, or exhumed in the state of Ceará, Brazil. ${ }^{9}$ Fungi were cultured from mucosal swabs, skin scrapings, hair, and lung biopsies; and also from clothing, coffins, and nearby soils. The organisms recovered were mainly saprobic molds (eg, Aspergillus, Mucor, Penicillium), keratinophilic fungi (Trichosporon), or yeasts (Candida albicans and $C$. parapsilosis). During the decomposition of the bodies, the greatest number of isolates was obtained from the bloated stage (143 cultures), compared with the putrefied (12), and skeletonized (26) stages. In the case of the associated clothing, coffins, and soil, 67 isolates were recovered from the skeletal stage, and none from the others. The authors concluded that, while differences in range of fungal isolates were found, they could not be used as effective biological markers of time of death.

In contrast to approaches based on the isolation and culture of fungi from human remains, the sizes of fungal colonies developed on skin (Figure 1), or other materials, have already been used successfully to estimate times of death or deposition. ${ }^{1}$ Examples of species we have found to be of particular value in this context are given in Table 1. We can now add to the cases to which we previously drew attention.

A young woman was found dead in a flat in West Yorkshire in January 1996. The forensic pathologist noted that there was some mummification and skin slippage, and it was necessary to determine how long the woman had been dead before her body was discovered. There were bluish green and gray mold colonies present, and the West Yorkshire Police Support Service took swabs from these, and then measured the sizes of the bluish green colonies; the gray ones were considered too diffuse to measure. The molds were identified as Penicillium and Mucor, but were not named to species. Over a period of 28 days, an experienced medical mycologist studied the growth rates of the fungi on two artificial media at a temperature similar to those where the body was found (ca $4^{\circ} \mathrm{C}$ ), and at room temperature $\left(\mathrm{ca} 21^{\circ} \mathrm{C}-24^{\circ} \mathrm{C}\right)$. After comparing the growth rates, the mycologist concluded that "death occurred a minimum of 3-4 weeks prior to 16 January 1996 when the area of growth on the right cheek was measured". ${ }^{10}$ This work contributed to a man being convicted of murder and sentenced to life imprisonment.

Fungal growth was reported on the surface of dismembered body parts of a fetus abandoned in a vineyard in Portugal. The growth of fungi led to the conclusion that the body had been stored in a confined space; it emerged that the body had been kept in a plastic bag in a refrigerator for some months prior to deposition. ${ }^{11}$

In the case of a young woman raped and murdered in Dundee, there were extensive fungal growths on exposed parts of the body, and these were evident in photographs taken at the deposition site. The body had been cremated before a mycologist was consulted, but having taken note of the low temperatures in the vicinity over the past weeks, it 


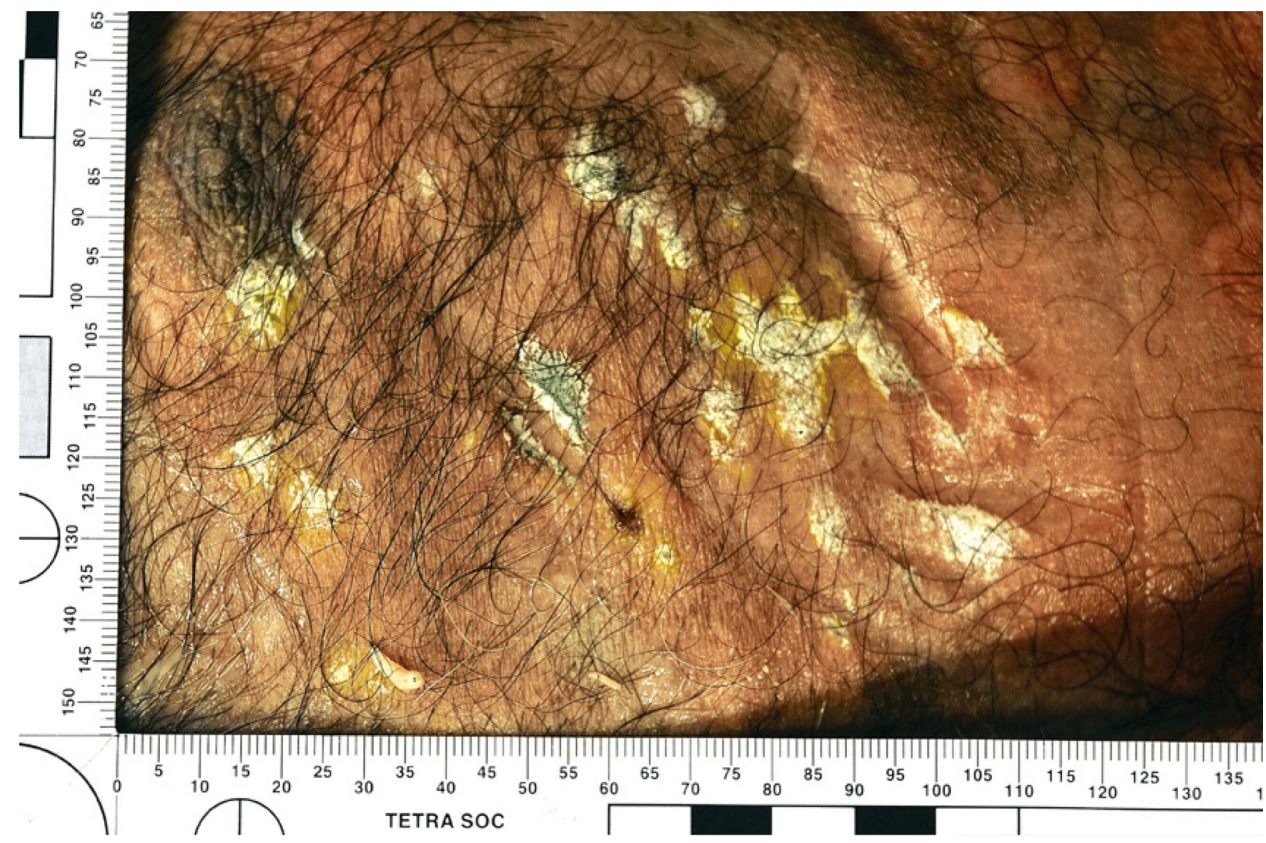

Figure I Greenish yellow patches of the fungus Penicillium griseofulvum developed directly on the skin of a torso of a human cadaver.

was estimated that the body had been there at least 2 weeks. Pollen and fungal spore trace evidence had linked a suspect to the victim and deposition site, and the PMI estimate agreed with the time when the victim and suspect had been caught on a video surveillance camera. The suspect had 13 previous convictions for sexual offences, and was sentenced to life imprisonment for the murder. ${ }^{12}$

Fungi on human remains may respond differently under different circumstances. A corpse left for 6 days in a wood in Italy under conditions of high humidity (80\%) and temperature $\left(35^{\circ} \mathrm{C}\right)$ in 2014 had been heavily degraded by dipteran larvae (maggots), and much of it was already skeletonized. ${ }^{13}$ The fungi recovered in this case included Mucor hiemalis and Penicillium pancosmium, and would not have been expected to establish so early in the cooler climates of more northern parts of Europe. The fly larval activity might also have been expected to have had a key role in enabling the fungi to colonize so quickly, so it is evident that every case has to be considered independently.

Table I Examples of mold species found on human skin of value in the estimation of postmortem interval

Byssochlamys nivea

Geotrichum candidum

Mucor hiemalis

Mucor plumbeus

Penicillium brevicompactum

Penicillium citrinum

Pseudogymnoascus pannorum
The extent of mold growth on the remains of cooked food (Figure 2) can also give indications of time. In a flat in northeast London in $2013,{ }^{14}$ evidence of this type contributed to the conviction of a mother for causing the death of a child by neglect. It was necessary to establish how long the mother had left her three children alone in a locked flat. The fungal colonies were measured and identified, and the results compared with published information on growth rates of the same

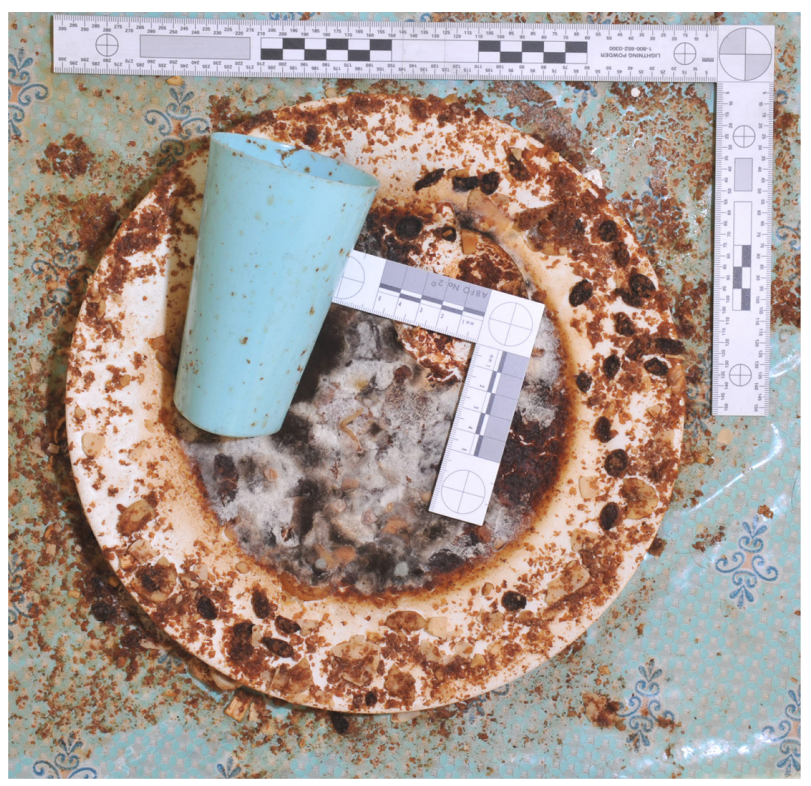

Figure 2 Plate of an unfinished meal left for 10-14 days showing extensive mold growths. The most conspicuous are Aspergillus niger (black) and Geotrichum candidum (white). 
fungi on artificial media at temperatures similar to those in the flat. The dimensions of the colonies of Aspergillus niger and Geotrichum candidum suggested the food had been left for a minimum of 10-14 days, and not just over a weekend as at first claimed; the mother pleaded guilty.

There is evidently a case for investigating officers paying more attention to the sizes of fungal colonies on human remains for estimation of $\mathrm{PMI}$, but the potential of fungi is rarely recognized or considered. Forensic pathologists are often unaware that such growths may be of evidential value and, may clean them from the cadaver without consideration. Comparing fungal colony sizes is of particular value if the fungi can be isolated into culture. They need to be grown in appropriate conditions which mimic, as closely as possible, those prevailing at the place where the body was found. It is not essential to identify any fungus - of critical importance is the response of the species obtained from the body to an experimental temperature range. This means that the comparative work can be undertaken in a basic microbiology laboratory by appropriately trained technicians. In order to encourage the use of the method, recommended protocols are currently being prepared for publication.

\section{Psychotropic and toxic substances}

The literature on toxic and psychotropic fungi, their effects, and treatment of cases of mushroom poisonings, continues to grow, and cannot be reviewed in depth here. We do, however, draw attention to publications and issues that can be important in a forensic context, particularly those involving suspicious death. Mushroom poisoning is a particular problem in the People's Republic of China, and a review of incidents in southern China found there had been 183 deaths out of $852(21.5 \%)$ patients who were hospitalized in the period 1994-2012. ${ }^{15}$ The number of different fungal species reported to be the cause of fatal poisonings continues to rise, with some mushrooms not previously recognized, or identified, being the cause of fatal incidents. Indications of the ingested species may be gleaned from symptoms ${ }^{13}$ but toxic fungi may be hitherto unknown species, or ones previously not considered to be poisonous. An example is Pleurocybella porrigens which was involved in 59 cases in 2004,19 of which were fatal. ${ }^{16}$ In the case of some fungal toxins, the symptoms they cause may mimic other conditions, such as cerebrovascular accident (stroke). ${ }^{17}$

With regard to poisonous fungi, the importance of precise identifications by specialists is clear, and this has been highlighted in several studies. ${ }^{18,19}$ There can be surprises even with supposedly well-known fungi purchased in stores. Recently, molecular work showed that a packet of dried "porcini mushrooms (Boletus edulis)" bought in a London shop, contained a mixture of three Boletus species that were new to science, ${ }^{20}$ fortunately in this case they appear not to have been poisonous species of the genus.

In toxicological analyses of human tissue samples, checks for poisoning by fungi are usually confined to the determination of the presence or absence of particular compounds implicated in a case. If the specific compounds are not found, investigation proceeds to fungi which are commonly found in the locality in question. Cost is often an issue, and toxicologists may cease further analysis when a significant level of a drug or other substance is detected..$^{21}$

In a recently reported case, ${ }^{22}$ dimethyltryptamine (DMT) was found in a sample taken from a man who died 4 days after attending a shamanistic ceremony where he was given Ayahuasca (an infusion made from South American plants from the rain forest). This infusion usually contains Psychotria viridis and often Banisteriopsis caapi. No other toxicological tests on the cadaver were requested by the police, but they had been informed that the deceased was in the habit of using magic mushrooms. A mushroom was found in the dead man's possession, and it was identified as Psilocybe semilanceata. As in many psychotropic fungi, $P$. semilanceata produces psilocybin which, in the body, becomes dephosphorylated to the pharmacologically active agent psilocin. To confirm that the deceased had consumed the fungus, contents from his stomach, ileum, and colon were examined microscopically. The colon proved to have abundant spores of the fungus (Figure 3) as well as the pollen of Cannabis, and the seeds of Papaver somniferum (opium poppy). Microscopical analysis of one flask found at the dead man's home also yielded Cannabis pollen, and another was encrusted with Psilocybe spores. It was established that the man had drunk suspensions of Cannabis and Psilocybe before the Ayahuasca and may have even been trying to obtain opiates from poppy capsules. He had not eaten for 4 days before his death so the seeds were unlikely to have come from bread or other food.

The police had intended to charge the shaman with manslaughter but, when the mixture of psychotrophic materials was found in his belongings and then in his gut, this was reduced to possession of a Class A drug. This case illustrates the value of analysis by light-microscopy in cases of suspicious death involving mushrooms. It also highlights the wisdom of sampling the lower gut (ileum, colon, possibly rectum, 


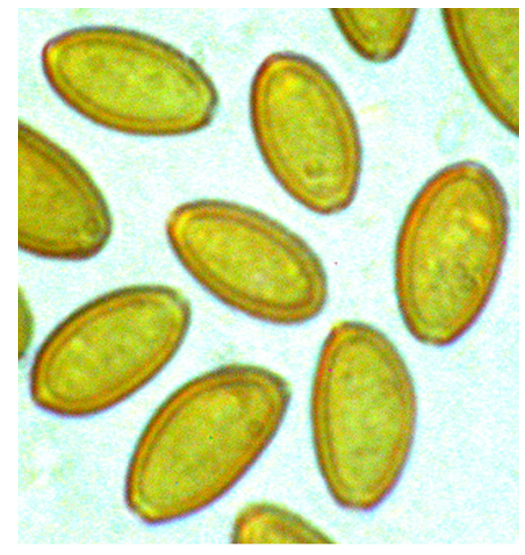

Figure 3 Spores of Psilocybe semilanceata as seen by light microscopy (Nomarski, differential interference contrast); the spores measure $10.5-15 \mu \mathrm{m} \times 6.5-8.5 \mu \mathrm{m}$.

and even feces), as well as stomach contents in cases of suspicious death. Sampling the lower gut is particularly important as symptoms of mushroom poisoning may not become evident for several days after ingestion by which time gut contents may have moved down to the colon and rectum.

\section{Mold growth in buildings}

It is generally accepted that extensive mold growth in buildings is correlated with respiratory health issues, ${ }^{23,24}$ but establishing cause and effect in any particular case is challenging.

Where there has been illness or death of individuals living in moldy buildings, the fungi deemed to have been the cause should be investigated before the case is dismissed. The sensitivity of any affected individual to specific fungal allergens, or the possibility of fungal growth in the lung, should always be checked. The forensic mycologist may be called upon to assist in such investigations, and sampling should be appropriate.

Considerable emphasis has been placed on sampling of aerial fungal spores in attempts to establish risks and correlations, but this method is problematical. It has been demonstrated that the airspora (airspora: pollen, plant spores, fungal spores [and other microscopic entities] in the air at any one time) fluctuates considerably both diurnally and seasonally. ${ }^{25}$ Further, some fungi are slime-spored rather than dry-spored, and do not readily discharge spores into the air. Others may be of concern because of the production of volatile compounds.

Great care must be taken to ensure that the species, developed on culture media from samples obtained from the building, are those growing in situ. Media are selective, and adventive spores may be cultured from the samples, rather than those produced by fungi actually growing in the property. Any growing colonies should be sampled by in situ taping; this will confirm any observations made by other sampling methods. ${ }^{26}$ Examples of some molds associated with indoor damp problems are shown in Table 2. Temporal estimates for colony growth can be made by using the same techniques as those described for mold growth on human remains and/ or associated objects (see Postmorten interval section). The dimensions of colony growth in vitro, under known temperatures, and for known time periods, can then be compared with those in the property; and a minimum age for colonization (Figure 4) can be estimated. This has provided particularly important information for evaluating whether insurance claims for water damage are fraudulent or valid.

\section{Soil profiles}

In the light of recent advances in molecular methods, it might be expected that they would be useful for the characterization of soil samples recovered from cadavers and objects, and linking them with specific locations. ${ }^{1}$ This is not an issue solely for forensic investigations, but for soil molecular ecology as a whole. An increasing number of techniques are becoming available, ${ }^{27}$ but fundamental issues need to be resolved before any results could be considered sufficiently robust for use in the forensic context. ${ }^{28}$

There has been some attempt to standardize the extraction of microbial DNA, even to the extent of the production of an

Table 2 Examples of mold fungi associated with indoor damp problems

Alternaria alternata

Aspergillus fumigatus

Aspergillus glaucus

Aspergillus niger complex

Aureobasidium pullulans

Chaetomium funicola

Chaetomium globosum

Cladosporium cladosporioides complex

Cladosporium herbarum complex

Doratomyces stemonitis

Myxotrichum chartarum

Penicillum brevicompactum

Scopulariopsis brevicaulis

Sporobolomyces roseus

Stachybotrys chartarum

Stachybotrys echinata

Stemphylium botyrosum

Trichoderma harzianum complex

Ulocladium atrum 


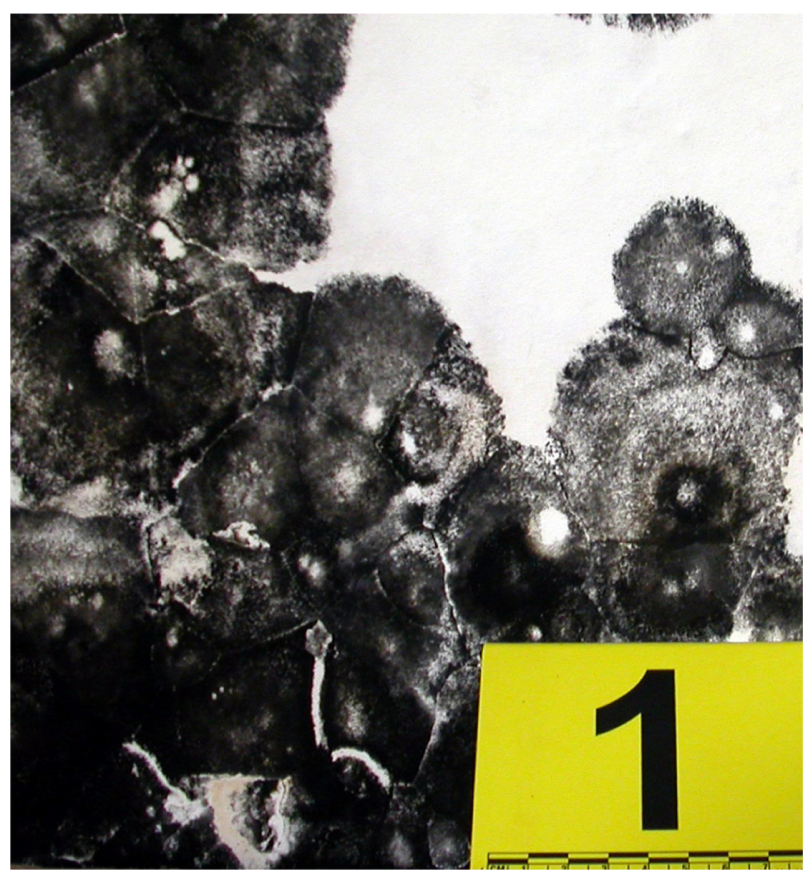

Figure 4 Colonies of Stachybotrys chartarum, the so-called "toxic mold", developed on a vertical plastered wall affected by rising damp.

ISO (International Standards Organization) standard, but a protocol for use in forensic laboratories is not yet available: ${ }^{29}$ "The problem at present is that it is difficult to reproduce the same result from soil samples", ${ }^{30}$ and "analyses of replicates is undertaken in less than one third of molecular ecology papers". ${ }^{31}$ Some success with bacteria has been claimed in a forensic case by comparing restriction digest fingerprints rather than sequences ${ }^{32}$ but, with fungi, there are major concerns regarding the use of high-throughput sequencing to assess fungal communities. ${ }^{33}$ Methods are becoming increasingly sophisticated as metagenomic approaches develop, and those interested in exploring molecular methods for assessing fungi in soil samples, are encouraged to follow the development of the molecular ecology literature. ${ }^{34}$

\section{Trace evidence}

An early, unpublished, use of lichen material as trace evidence has recently become known. Fragments of the lichen Lecanora dispersa, were found on trousers of one of three men involved in a factory break-in Coventry in 1962. The lichen fragments formed part of the evidence that helped the West Midland Forensic Science Laboratory establish they had entered the property over a concrete wall. ${ }^{35}$

Several cases in which fungal spores and remains had been used as trace evidence in criminal investigations were reported on previously, ${ }^{1}$ and a fuller account of one of those, a rape in Wiltshire, has now been published. ${ }^{36}$ In many cases,
DNA may not be available or, as in the case of consensual vs rape, it may be irrelevant. The rape in Wiltshire demonstrates that, when combined with palynological results, fungal data are especially valuable.

We continue to use fungal data in investigations to assist police forces, and mention two additional illustrative examples here. In the case of a rape and murder in Dundee, ${ }^{12}$ comparison of the independent pollen and fungal spore profiles retrieved from 1) the victim's body, 2) the place of deposition, and 3) shoes of the suspect, were crucial in securing a conviction for murder. The scene was unusual in being planted with exotic tree and shrub species, and the local municipal authorities had covered the ground with macerated woody mulch derived from garden waste, parks, and gardens; the mulch consisted of a unique mixture of woody material. Sixteen fungi were common to the shoes of the suspect, the clothing of the victim, and the crime scene. It was of particular note that the fungal remains included minute shield-like sporophores (spore producing structures) from three species, and these could only be expected to be picked up by a direct physical contact.

In the second case, an elderly man and wife were badly injured by assailants during an aggravated burglary in Lincolnshire. The couple made their living by selling firewood bundles made up from trees cleared from other properties, especially gardens and estates. Data obtained from the various palynological profiles suggested that much of the trace particulate material was in common with the crime scene rather than the alibi sites described by the suspects. They claimed that all the relevant pollen and spores had been picked up from a local farm, and an adjacent fishing lake. There were 65 different taxa of fungal spores recognized in the case material (Table 3 ) and many were retrieved from the vehicle and boots of the two suspects. Of 29 different kinds of fungal spores found at the crime scene, 28 were obtained from the boots and escape vehicle, ${ }^{37}$ and none of these was found in the alibi samples. One of the critical species, Testudina terrestris, was a fungus only occurring on conifers alien to the UK and, until it was found in this case, had only previously been reported from the Royal Botanic Gardens Kew. The fungal and palynological data corroborated each other; the suspects pleaded guilty and received custodial sentences.

The identification of fungal spores can be a timeconsuming and so, a costly process. It may involve extensive literature searches, comparison with preserved reference collections, and sending pictures to specialists on specific fungal groups around the world. However, whether the 
Table 3 A summary of fungal palynomorphs from the crime scene, and alibi site, a car used in the escape, and the boots of each of the two suspects, in an aggravated burglary

\begin{tabular}{|c|c|c|c|c|c|}
\hline \multirow[t]{2}{*}{ Fungal palynomorph } & \multirow[t]{2}{*}{ Crime scene } & \multirow[t]{2}{*}{ Alibi sites } & \multirow[t]{2}{*}{ Car footwells } & \multicolumn{2}{|l|}{ Boots } \\
\hline & & & & Suspect I & Suspect 2 \\
\hline Farlowiella carmichaelianum & 0.9 & & + & + & + \\
\hline Type SD & 0.7 & & + & + & + \\
\hline Oncopodiella trigonella & 0.6 & & I.I & + & + \\
\hline Scleroderma bovista & 0.3 & & 0.5 & & \\
\hline Testudina terrestris & + & & 2.0 & & \\
\hline Periconia digitata & + & & 1.3 & & 2.4 \\
\hline Bactrodesmium betulicola cf & + & & 0.9 & & \\
\hline Endophragmiella fagicola & + & & 0.5 & & \\
\hline Clasterosporium flexum & + & & 0.3 & & + \\
\hline Monodictys sp. I & + & & 0.5 & + & + \\
\hline Urocystis sp. & + & & 0.4 & & + \\
\hline Type DPP & + & & 0.3 & & \\
\hline Monodictys sp. 2 & + & & + & 0.5 & 0.5 \\
\hline Splanchnonema pupula cf. & + & & + & + & + \\
\hline Sporormiella intermedia & + & & + & + & + \\
\hline Brachysporiella laxa & + & & + & & \\
\hline Alternaria tenuissima & + & & + & & \\
\hline Delitschia variispora cf. & + & & + & & \\
\hline Tetraploa aristata & + & & + & & + \\
\hline Phaeoseptoria sp. & + & & + & & + \\
\hline Type BS & + & & + & & \\
\hline Melanospora zamiae & + & & & 2.2 & \\
\hline Dictyosporium toruloides & + & & & + & + \\
\hline Zopfiella latipes & + & & & + & + \\
\hline Ascochyta acori cf. & + & & & + & \\
\hline Melanospora sp. & + & & & & + \\
\hline Pestalotiopsis sp. & + & & & & + \\
\hline Rhopalomyces elegans & + & & & & \\
\hline Sphaeropsis malorum & & & 0.9 & & \\
\hline Trichocladium asperum & & & + & & \\
\hline Microthyriaceae & & & + & & + \\
\hline Rhopalomyces magnum & & & & + & + \\
\hline \multicolumn{6}{|l|}{ Sphaeropsis sapinea } \\
\hline \multicolumn{6}{|l|}{ Diplodia mutila } \\
\hline Bactrodesmium obovatum & & & & + & \\
\hline Hydnobolites cerebriformis & & & & + & \\
\hline Type LDS & 9.4 & 1.0 & 2.1 & & 2.4 \\
\hline Type T & 1.0 & + & 19.1 & I.I & + \\
\hline Type BW & 0.4 & 1.5 & 1.2 & + & 10.8 \\
\hline Type DP & + & 1.8 & 0.3 & & \\
\hline Caryospora callicarpa & + & 0.5 & & 0.6 & \\
\hline Glomus-type & + & + & + & + & \\
\hline Type CC & + & + & + & & \\
\hline Type LLB & + & + & + & & \\
\hline Type RB & + & & & & \\
\hline Type LPP & + & & & & \\
\hline Type DPRP & + & & & & \\
\hline Type VSTR & + & & & & \\
\hline Type PR & + & & & & \\
\hline Type TE & + & & & & \\
\hline Type SPD & + & & & & \\
\hline Type EB & + & & & & \\
\hline Type BU & & 2.2 & & & \\
\hline
\end{tabular}


Table 3 (Continued)

\begin{tabular}{|c|c|c|c|c|}
\hline \multirow[t]{2}{*}{ Fungal palynomorph } & \multirow[t]{2}{*}{ Crime scene } & \multirow[t]{2}{*}{ Car footwells } & \multicolumn{2}{|l|}{ Boots } \\
\hline & & & Suspect I & Suspect 2 \\
\hline Type EM & & 2.3 & & \\
\hline Type PSS & & 0.8 & & \\
\hline Type RSL & & + & + & \\
\hline Type SWDM & & + & + & \\
\hline Type LSM & & + & & + \\
\hline Type RBU & & + & & \\
\hline Type ELB & & + & & \\
\hline Type X & & + & & \\
\hline Type LGR & & & + & \\
\hline Type BBL & & & + & + \\
\hline Type SE & & & & + \\
\hline
\end{tabular}

Notes: Figures represent numbers of fungal spores expressed as a percentage of total non-fungal palynomorphs, plus fungal spores. Plus signs indicate values $<0.3 \%$ of the total count. "Type" indicates an informal morphological spore category in which the spores have not been identified; the letter codes used are arbitrary identifiers. Data from the report for Lincolnshire Police. ${ }^{37}$

spores are named or not, if identical ones are obtained from different exhibits, they can still be of value in a case. Identification is preferred because if they are named, they can provide additional value with respect to the substrates and/or host plants on which they are known to grow. This may provide ecological information on both the plants and soils, and might facilitate the elimination of certain locations in an investigation. Precise identification makes it possible to check how commonly any species is reported in pertinent databases. In the UK, the Fungal Records Database of Britain and Ireland (http://www.fieldmycology.net/GBCHKLST/) is especially valuable; it contained $1,984,344$ records on 9 August 2015.

We mention the use of fungal spore data as trace evidence here as, in addition to the issue of forensic pathologists cleaning away visible mold colonies from human remains (see Postmorten interval section), they need to be aware that there may be fungal spores, pollen, and other microscopic particulates, of potential evidential importance in hair, exposed tissues, nasal passages, mud smears, and attached vegetation. Protocols for the recovery and processing of palynomorphs (ie, pollen, spores, and other microscopic entities), and use as trace evidence from environmental samples, human remains, and various objects, are available separately. ${ }^{38}$

\section{Conclusion}

From this review of the use of fungal data in a broad spectrum of forensic situations, it will be evident that mycology has much to contribute to the investigation of both criminal and civil cases (in the latter, particularly for insurance fraud). The applications discussed here are not suggestions of possibilities yet to be explored, but ones which have been used in actual cases and tested in the Courts. In order further to realize the potential, however, it will be necessary for investigating officers to become more aware of the possibilities provided by spores and whole fungi, and to recognize situations where mycological evidence might provide critical evidence. In such cases, specialist advice should be sought. There is a need for those involved in all aspects of forensic medicine (especially pathology and toxicology), to be aware of the evidential value of fungi, especially with respect to trace evidence, timing of events, and demonstrating psychotropic substances, and poisons. They may provide important evidence which might otherwise be missed.

\section{Disclosure}

The authors report no conflicts of interest in this work.

\section{References}

1. Hawksworth DL, Wiltshire PEJ. Forensic mycology: the use of fungi in criminal investigations. Forensic Sci Int. 2011;206:1-11.

2. Said Al Na'imi K. Basics of forensic mycology. In: Coyle HM, editor. Nonhuman DNA Typing: Theory and Casework Applications. Boca Raton: CRC Press; 2008:135-165.

3. Bellini E, Ambrosio E, Zotti M, Nucci G, Gabbriella G, Vanezis P. The usefulness of cadaveric fungi as an investigation tool. Am J Forensic Med Pathol. Epub 2015 Oct 23.

4. Metcalf JL, Parfrey LW, Gonzalez A, et al. A microbial clock provides an accurate estimate of the postmortem interval in a mouse model system. eLife. 2013;2:e01104,

5. Dent BB, Forbes SL, Stuart BH. Review of human decomposition processes in soil. Environ Geol. 2004;45:576-585.

6. Bogomolov DV, Amanmuradov AKh. Mycobiotic studying of human remains for forensic-legal definition of death-age and burial place. Prod Ékspert Medit. 2004;4:19-21.

7. Bogomolov DV, Amanmuradov AKh, Piriazeva EA, Bogomolova IN, Dolzhanskii OV. A study of cadaveric mycobiota at the late stages of post-mortem changes within the forensic-medical verification of death coming and of bury place. Sud-Medit Ekspert. 2004;47(4):14-18.

8. Bogomolov DV, Trgashin AV, Amanmuradov AKh, et al. Mycological and entomological methods for estimation of the time since death in forensic medicine. Sud-Medit Ekspert. 2011;54(5):23-25. 
9. Sidrim JJC, Moreira Filho RE, Cordeiro RA, Rocha MF, Monteiro AJ, Brilhante RSN. Fungal microbiota dynamics as a postmortem investigation tool: focus on Aspergillus, Pencillium and Candida species. J Appl Microbiol. 2010;108:1732-1756.

10. Evans EGV. Regina V. William Kerr/Christopher Moody. Statement of Emlyn Glyn Vaughan Evans. Report to West Yorkshire Police, Leeds; 1996.

11. Simón A, Silva BS, Oliveira C, Corte Real F. Fetal autopsy of a dismembered body. In: 19th IAFS World Meeting, 9th WPMO Triennial Meeting, 5th MAFS Meeting, Funchal - Madeira - Portugal, September 12-17, 2011; International Association for Forensic Science, Funchal, 66. Abstract Book.

12. Wiltshire PEJ, Hawksworth DL, Webb JA, Edwards KJ. Two sources and two kinds of trace evidence: enhancing the links between clothing, footwear and crime scene. Forensic Sci Int. 2015;254:230-242.

13. Bellini E, Ambrosio E, Di Piazza S, Gabbrielli M, Zotti M. Microfungi on human corpse in the skeletalization stage. In Abstracts, EAFS 7, Seventh European Academy of Forensic Sciences Conference, Prague; 2015, P 0127.

14. Hawksworth DL. Operation Jasmine Hill: Report on Mould Growth on Exhibits Recovered from the Property. Report to the Metropolitan Police, London; 2013.

15. Chen Z, Zhang P, Zhuang Z. Investigation and analysis of 102 mushroom poisoning cases in southern China from 1994 to 2012. Fungal Divers. 2014;64:123-151.

16. Gonmori K, Fujita H, Yokoyama K, Watanabe K, Suzuki O. Mushroom toxins: a forensic toxicological review. Forensic Toxicol. 2011;29: 85-94.

17. Cornelli I, Lippi G, De Blasio A, Cervellin G. Accidental mushroom poisoning mimicking stroke. A case report and literature review. Acta Biomed. 2013;84:229-233.

18. Schenck-Jaeger KM, Rauber-Lüthy C, Bodmer M, Kupferschmidt H, Kullak-Ublick GA, Ceschi A. Mushroom poisoning: a case study on circumstances of exposure and patterns of toxicity. Eur J Intern Med. 2012;23:e85-e91.

19. Cassidy N, Duggan E, Tracey JA. Mushroom poisoning in Ireland: the collaboration between the National Poisons Information Centre and expert mycologists. Clin Toxicol (Phila). 2011;49:171-176.

20. Dentinger BTM, Suz LM. What's for dinner? Undescribed species of porcini in a commercial packet. Peer J. 2014;2:e570.

21. Anderson R, Torrance H. Forensic toxicology. In: White P, editor. Crime Scene to Court: The Essentials of Forensic Science. 2nd edn. London: Royal Society of Chemistry Publishing; 2010:390-437.

22. Wiltshire PEJ, Hawksworth DL, Edwards KJ. Light microscopy can reveal the consumption of a mixture of psychotropic plant and fungal material in a suspicious death. J Forensic Leg Med. 2015;34:73-80.

23. WHO [World Health Organization]. Guidelines for Indoor Air Quality: Dampness and Mold. 2009. WHO Regional Office for Europe, Copenhagen.
24. Miller JD. Health effects from mold and dampness in housing in western societies: early epidemiology studies and barriers to further progress. In: Adan OCG, Samson RA, editors. Fundamentals of Mold Growth in Indoor Environments. Wageningen: Wageningen Academic Publishers; 2011:183-210.

25. Hyvärinen A, Vahteristo M, Meklin T, Hantunen M, Nevalainwen A. Temporal and spatial variation of fungal concentrations in indoor air. Aerosol Sci Technol. 2001;35:688-695.

26. Hawksworth DL. Naming fungi involved in spoilage of food, drink, and water. Current Opin Food Sci. 2015;5:23-28.

27. Hirsch PR, Mauchline TH, Clark IM. Culture-independent molecular techniques for soil microbial ecology. Soil Biochem. 2010;42: 878-887.

28. Dawson LA, Hillier S. Measurement of soil characteristics for forensic applications. Surf Interface Anal. 2010;42:363-377.

29. Young JM, Rawlence NJ, Weyrich LA, Cooper A. Limitations and recommendations for successful DNA extraction from forensic soil samples: a review. Sci Justice. 2014;54:238-244.

30. Goodwin W, Linacre A, Hadi S. An Introduction to Forensic Genetics. 2nd ed. Chichester: Wiley-Blackwell; 2011.

31. Prosser JI. Replicate or lie. Environ Microbiol. 2010;12:1806-1810.

32. Concheri G, Bertoldi D, Polone E, Otto S, Larcher R, Squartini A. Chemical elemental distribution and soil DNA fingerprints provide the critical evidence in murder case investigation. PLoS One. 2011;6(6):e20222.

33. Lindahl BD, Nilsson RH, Tedersoo L, et al. Fungal community analysis by high-throughput sequencing of amplified markers - a user's guide. New Phytol. 2013;199:288-299.

34. Myrold DD, Nannipieri P. Classical techniques versus omics approaches. In: Nanninpieri P, Pietramellara G, Renella G, editors. Omics in Soil Science. Caister: Caister Academic Press; 2014:178-187.

35. Galloway DJ. Peter James (1930-2014) and forensic lichenology. Bull Br Lichen Soc. 2014;115:32-35.

36. Wiltshire PEJ, Hawksworth DL, Webb JA, Edwards KJ. Palynology and mycology provide separate classes of probative evidence from the same forensic samples: a rape case from southern England. Forensic Sci Int. 2014;244:186-195.

37. Wiltshire PEJ. Operation Theatre. Report on the comparison of palynological profiles of a vehicle, and three pairs of footwear, with those from comparator samples from a crime scene and other pertinent places. Report for Lincolnshire Police; 2010.

38. Wiltshire PEJ. Protocols for forensic palynology. Palynology. 2015(10). Available from http://www.researchgate.net/publication/283699052_ Protocols_for_forensic_palynology. Accessed 24 November, 2015.
Research and Reports in Forensic Medical Science

\section{Publish your work in this journal}

Research and Reports in Forensic Medical Science is an international, peer-reviewed, open access journal publishing original research, reports, reviews and commentaries on all areas of forensic medical science. The manuscript management system is completely online and includes a

\section{Dovepress}

very quick and fair peer-review system. Visit http://www.dovepress.com/ testimonials.php to read real quotes from published authors. 